\title{
EDITORIAL
}

\section{Change, Continuity and Challenge in African Studies}

\author{
Geoffrey Hawker \\ Editor-in-Chief \\ Macquarie University \\ geoffrey.hawker@mq.edu.au \\ editor@afsaap.org.au
}

With this edition of ARAS a transition in the editorial team takes place, but the purposes and ambitions of the journal remain constant. We have lost our long serving editor Dr Tanya Lyons, president of the Association also from 2012 to2017. It is important to explain to readers of the journal and to members of the Association that the change was forced upon us by a swingeing round of retrenchments at Flinders University that made it impossible for Tanya Lyons to continue to act as editor in the way that an academic securely placed can do.

Regular readers of this journal may well see more in this than just another round of economising in the tertiary sector. Tanya's editorials over the years have demonstrated that Africa-related teaching and research needs tenacious defence at all times in Australia's universities when the 'grain' of research funding, status and promotion seems to favour attention to the first world or to the developing and developed nations of Asia. The "Rudd period" of enhanced funding for African research and postgraduate study is now a diminishing memory. But if Tanya's work as a researcher and teacher in and on Africa is lost to one university, she is not lost to African scholarship more generally. At this time, the editorial team records their deep appreciation of her service both to the journal and to the Association.

The editorial team now in place is listed at the end of this editorial, and the international advisory board in the inside cover of this issue in the usual way. Invitations are open to act as guest editor of the journal for special issues. One such special edition is already in prospect: A Call for Papers on the theme of Governance in Africa under the editorship of Anne Bartlett is announced with this edition of ARAS. Details are shown below. 
We call the attention of intending guest editors and authors generally to the guidance on style, length and associated issues on the inside front cover of this issue; and earnestly suggest a close reading also of the further guidelines on the AFSAAP web page referenced there.

Finally, we note that in November this year the annual conference of the Association will be held at the University of Otago, Dunedin, New Zealand, convened by Professor Tony Binns. Readers are encouraged to attend and to circulate notice of the conference to others. The Call for Papers and details of registration and payment are in this edition of ARAS - see below.

\section{$* * *$}

The work of the Association certainly continues apace, in addition to the scholarly articles, discussions, interviews and reviews supported by this journal. Events in Africa in recent months have focused world attention especially on the Sudan and members of the Association have been active in a number of ways in calling publicly for governments, non-governmental organisations and business interests to exercise influence where they can to promote a durable peace. Where possible and appropriate, members with established networks of contacts in diplomatic and political circles have also made direct approaches to individuals who have a capacity to intervene in the Sudanese situation. Such interventions are beyond the function of a journal such as this, but the description and analysis of African life, extending well into critique of the world's dealings with the nations and the peoples of the continent, is within our remit and must support reasoned approaches to the crises of our times.

\section{$* * *$}

This edition of ARAS presents a range of scholarly articles, commentary on unfolding issues in Africa, an interview with a leading "Australian Africanist", and reflections by the president of AFSAAP on the status of African studies in Australia, set in the context of related work in the USA and Europe. The four leading articles in this edition reflect well the twin focus of the journal as it has emerged over twenty years: on cross-disciplinary studies of Africa, across space and periods of time, and on the experiences of the African diaspora in Australasia.

The first two deal with historically formed issues of importance, both dealing with Ghana but with distinct substance and from very different perspectives. Kirsty Wissing explores Akwamu understandings of the Volta 
and other rivers in Ghana - valued for their life-giving qualities - when they become the opposite: the cause of death by drowning. Through customary ritual practices, traditional representatives separate the Akwamu state, or society, from an individual's bad, watery death and restore humanenvironment and inter-human order in social life on land. Stir the waters, however, and Akwamu understandings of rivers highlight a hierarchy in human-environment relations as well as undercurrents of power between humans. By analysing beliefs, interpretations, and ritual behaviours in response to drowning, the author reconceptualises Akwamu dynamics of power in reflections on environments as justice. An earlier version of this fascinating paper was the winner of the Cherry Gertzel / AFSAAP 2017 Postgraduate Prize.

The authors of the second article (James Boafo, Divine Odame Appiah and Peter Dok Tindan) explain the contemporary situation of farmers in Ghana's bread-basket, the Brong-Ahafo region, who are tempted from food production for the local market to produce instead for the international commodities market, where prices are relatively high, though by no means always 'trickling down' to the farmers. Their case study of the production of cashew nuts suggests that patterns of dependence formed in the colonial period are being reproduced in our times, actively assisted by government policy that seems unwilling to consider the long terms issue of underdevelopment.

Taken together, the two articles point to the continued vigour of postgraduate work on African issues in some Australian universities, notwithstanding the general tenor of cutback and indifference prevailing generally.

The two papers following deal with the experiences of the African diaspora in Australasia in recent years. Those experiences have been the source of many articles in ARAS as the citizens and residents of Australia and New Zealand with African heritage make their way in challenging contexts - or, in all too many cases, struggle to establish a new way of life. Each article deals with aspects of that struggle, neither painting a picture of easy adjustment. Yet, each in different ways suggests that immigrants alone do not make the adjustments but that the host society also does, however reluctantly and still incompletely. Francesca Perugia examines the problems of access to stable housing in metropolitan Perth, concentrating on the experience of Sudanese immigrants and refugees. Her quantitative analysis draws upon census data in a strikingly original way and forms a sound basis for policy argument and prescription. Access to secure and affordable housing is notoriously a problem across Australian society, to be sure, and a 
study like this reinforces our knowledge that socio-economic disadvantage and marginalised ethnicity are intertwined issues that call for radical thinking and solidarity across sectors of Australian society that are just coming to know and understand each other.

The second article of this pair counter-poses issues of vulnerability experienced by immigrants and refugees (in this case drawn from a sample in the south-east area of Queensland) with the lived capacity of individuals to show resilience in overcoming a shifting set of obstacles involving economic, social and cultural disadvantage and negative discrimination. This is a qualitative study that can be read as a companion piece to an earlier study by two of the authors ("“It still matters': The role of skin colour in the everyday life and realities of black African migrants and refugees in Australia", Hyacinth Udah and Parlo Singh, $A R A S, 39,2$ December 2018, pp. 19-47: http://afsaap.org.au/assets/39 2 19-47.pdf ), and it shows that resilience can be found across age, gender, occupation and education. Not all lives show resilience it is true but many do, and the authors (those mentioned above, together with Dorothee Hölscher and Jennifer Cartmel) emphasise that the policy responses of government and employers can be the context that fosters a sense of resilience. Anti-racist education in schools, classrooms and workplaces is part of that context, they suggest, as is continued attention to assessing educational and overseas work experience fairly.

In the "Interviews, Commentaries and Viewpoints" section we return to Africa, as it were, with diverse contributions to our knowledge. Peter Alegi and Peter Limb report verbatim their interview with Norman Etherington, the "titan of African History in Australia", who explains his intellectual development, his early sojourns in Africa and the well springs of his many publications, not least the cartographic. It is an encouraging read, even though his is a career unlikely to be matched!

Anthony Hevron and Michael Crowley take us in a different direction, into the sharply contested territory of the motivations and outcomes of Chinese activity in Africa. Their focus on investment, and perhaps the price that will be paid by those governments that accept the funding, contributes to a debate that seems likely to increase in intensity until the outcomes of such 'development' are indeed easier to assess. Their work can be read in conjunction with other papers in this debate, or better perhaps, controversy, that appeared in a special issue of ARAS (volume 38 number 2, 2017, online at http://afsaap.org.au/ARAS/2017-volume 38). We welcome further contributions that can add to our understanding of developments in Africa that may suggest lessons well beyond the continent. 
Finally in this section Peter Limb, the AFSAAP president, draws on his extensive experience across the continents to map African studies in a broad way, including in his comparative review universities, publishers, libraries, the varied African communities of the diaspora, and the students of African life, past and present but also imagined in the future. His reflections on the prospects for African studies in Australia have a positive tone but also challenge those of us now active to think ahead - to renew and strengthen our focus on Africa itself, its people and their issues, at the same time as we work to strengthen the linkages between those in Australia who are willing to engage with Africa in some at least of its many dimensions.

\section{Editorial Team 2019-2020:}

Geoffrey Hawker (editor-in-chief), Peter Limb (president AFSAAP), Edson Ziso (secretary AFSAAP) and Tass Holmes and Mengistu Amberber (elected members), with Anne Bartlett (vice-president and convener of the 2018 conference). 